NASA/TM-2002-211832

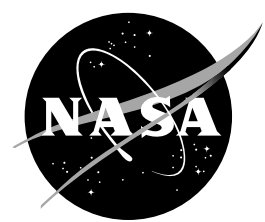

\title{
An Investigation of Surge in a High-Speed Centrifugal Compressor Using Digital PIV
}

Mark P. Wernet and Michelle M. Bright

Glenn Research Center, Cleveland, Ohio

Gary J. Skoch

U.S. Army Research Laboratory, Glenn Research Center, Cleveland, Ohio 
Since its founding, NASA has been dedicated to the advancement of aeronautics and space science. The NASA Scientific and Technical Information (STI) Program Office plays a key part in helping NASA maintain this important role.

The NASA STI Program Office is operated by Langley Research Center, the Lead Center for NASA's scientific and technical information. The NASA STI Program Office provides access to the NASA STI Database, the largest collection of aeronautical and space science STI in the world. The Program Office is also NASA's institutional mechanism for disseminating the results of its research and development activities. These results are published by NASA in the NASA STI Report Series, which includes the following report types:

- $\quad$ TECHNICAL PUBLICATION. Reports of completed research or a major significant phase of research that present the results of NASA programs and include extensive data or theoretical analysis. Includes compilations of significant scientific and technical data and information deemed to be of continuing reference value. NASA's counterpart of peerreviewed formal professional papers but has less stringent limitations on manuscript length and extent of graphic presentations.

- TECHNICAL MEMORANDUM. Scientific and technical findings that are preliminary or of specialized interest, e.g., quick release reports, working papers, and bibliographies that contain minimal annotation. Does not contain extensive analysis.

- CONTRACTOR REPORT. Scientific and technical findings by NASA-sponsored contractors and grantees.
- CONFERENCE PUBLICATION. Collected papers from scientific and technical conferences, symposia, seminars, or other meetings sponsored or cosponsored by NASA.

- SPECIAL PUBLICATION. Scientific, technical, or historical information from NASA programs, projects, and missions, often concerned with subjects having substantial public interest.

- TECHNICAL TRANSLATION. Englishlanguage translations of foreign scientific and technical material pertinent to NASA's mission.

Specialized services that complement the STI Program Office's diverse offerings include creating custom thesauri, building customized databases, organizing and publishing research results ... even providing videos.

For more information about the NASA STI Program Office, see the following:

- Access the NASA STI Program Home Page at http://www.sti.nasa.gov

- E-mail your question via the Internet to help@sti.nasa.gov

- Fax your question to the NASA Access Help Desk at 301-621-0134

- Telephone the NASA Access Help Desk at 301-621-0390

- Write to:

NASA Access Help Desk

NASA Center for AeroSpace Information 7121 Standard Drive

Hanover, MD 21076 
NASA/TM-2002-211832

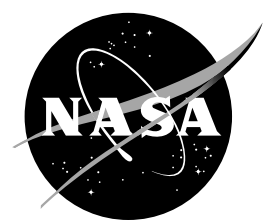

\section{An Investigation of Surge in a High-Speed Centrifugal Compressor Using Digital PIV}

Mark P. Wernet and Michelle M. Bright

Glenn Research Center, Cleveland, Ohio

Gary J. Skoch

U.S. Army Research Laboratory, Glenn Research Center, Cleveland, Ohio

National Aeronautics and

Space Administration

Glenn Research Center 


\section{Acknowledgments}

The authors would like to thank Tony Zaldana, Angela Surgenor, Stephen Helland, and Tom Jett for their support in the operation of the centrifugal compressor facility. We would also like to thank Mr. W.T. John for his assistance in the setup and installation of the DPIV system. A special thanks to Tony Strazisar and Jerry Wood for their many helpful comments and suggestions throughout this research program.

Available from

NASA Center for Aerospace Information 7121 Standard Drive

Hanover, MD 21076
National Technical Information Service 5285 Port Royal Road Springfield, VA 22100 


\title{
An Investigation of Surge in a High Speed Centrifugal Compressor Using Digital PIV
}

\author{
Mark P. Wernet and Michelle M. Bright \\ National Aeronautics and Space Administration \\ Glenn Research Center \\ Cleveland, Ohio 44135 \\ Gary J. Skoch \\ U.S. Army Research Laboratory \\ Glenn Research Center \\ Cleveland, Ohio 44135
}

\begin{abstract}
Compressor stall is a catastrophic breakdown of the flow in a compressor, which can lead to a loss of engine power, large pressure transients in the inlet/nacelle and engine flameout. The implementation of active or passive strategies for controlling rotating stall and surge can significantly extend the stable operating range of a compressor without substantially sacrificing performance. It is crucial to identify the dynamic changes occurring in the flow field prior to rotating stall and surge in order to successfully control these events. Generally, pressure transducer measurements are made to capture the transient response of a compressor prior to rotating stall. In this investigation, Digital Particle Imaging Velocimetry (DPIV) is used in conjunction with dynamic pressure transducers to simultaneously capture transient velocity and pressure measurements in the non-stationary flow field during compressor surge. DPIV is an instantaneous, planar measurement technique which is ideally suited for studying transient flow phenomena in high speed turbomachinery and has been used previously to successfully map the stable operating point flow field in the diffuser of a high speed centrifugal compressor. Through the acquisition of both DPIV images and transient pressure data, the time evolution of the unsteady flow during surge is revealed.
\end{abstract}

\subsection{Introduction}

Turbomachines are used in a wide variety of engineering applications for power generation, pumping and aeropropulsion. The need to reduce acquisition and operating costs of aeropropulsion systems drives the effort to improve propulsion system performance. Improving the efficiency in turbomachines requires understanding the flow phenomena occurring within rotating machinery. In addition to improving efficiency at design conditions, work is also in progress to investigate compressor stall. Compressor stall is a catastrophic breakdown of the flow in a compressor, which can lead to a loss of engine power, large pressure transients in the inlet/nacelle and engine flameout. The distance on a performance map between the operating point of a compressor and its stall point is referred to as the "stall margin". Stall margin is required to account for increased clearances within the compressor caused by throttle transients and component deterioration with age. Optimal engine designs tend towards minimal stall margins since modifications to increase the stall margin typically result in heavier, less efficient and less loaded compressors. However, if instead active or passive stall control is employed, stable operation over a wider range of flow conditions (improved stall margin) can be obtained with a minimal loss in performance as 
demonstrated by Weigl et al. (1997). The instantaneous flow field capture capability of DPIV is well suited to the task of studying the change in flow conditions surrounding the development of stall precursors, stall cell propagation and eventually compressor surge.

Digital PIV provides near real-time flow field measurements through the use of refined data processing techniques combine with advances in CCD sensor technology. Digital PIV is a planar measurement technique wherein a pulsed laser light sheet is used to illuminate a flow field seeded with tracer particles small enough to accurately follow the flow. The positions of the particles are recorded on a digital CCD camera at each instant the light sheet is pulsed. In high-speed flows, pulsed Nd:YAG lasers are required to provide sufficient light energy $(\sim 100 \mathrm{~mJ} /$ pulse $)$ in a short time interval $(<10 \mathrm{nsec})$ to record an unblurred image of the particles entrained in the flow. The data processing consists of either determining the average displacement of the particles over a small interrogation region in the image or the individual particle displacements between pulses of the light sheet. Knowledge of the time interval between light sheet pulses then permits computation of the flow velocity. While each processing technique has some inherent benefits, the appropriate choice depends on the characteristics of the flow and the recorded image quality.

Numerous researchers have employed various PIV techniques to study the unsteady flows in rotating machines. Paone et al. (1988) used PIV to make blade-to-blade plane velocity measurements in a centrifugal compressor. Although not a rotating machine application, Bryanston-Cross et al. (1992) described photographic PIV measurements obtained in a transonic turbine cascade rig. The light sheet illumination was introduced via an $8.0 \mathrm{~mm}$ diameter hollow turbulence generating bar which was already part of the experimental rig. Rothlübbers et al. (1996) used digital PIV to study the flow in a radial pump. Low seed particle concentrations were identified as not suitable for rotating machine studies, where high spatial resolution measurements are required. Oldenburg and Pap (1996) used a digital PIV setup to investigate the flow field in the impeller and volute of a centrifugal pump. The lab scale facility used water as the working fluid and a transparent impeller. Gogineni and Goss (1997) have described a two-color DPIV technique, which should be applicable to turbomachinery. A high resolution $(3000 \times 2000$ pixel $)$ single CCD sensor color camera is employed to record the particle images at two instances in time on a single CCD image frame using red and green illumination pulses. Day-Treml et al. (1998) used a high resolution (2000×2000 pixel) digital camera to obtain DPIV measurements of rotorstator interactions in a low speed turbine facility. Again a light sheet probe was used to introduce the light sheet into the flow and the measured velocities were on the order of $30 \mathrm{~m} / \mathrm{s}$. BryanstonCross et al. (1997) performed particle tracking measurements of the high speed flow in the stator trailing edge region of a transonic axial compressor blowdown facility. Wernet (1997) obtained high spatial resolution DPIV measurements in the rotor blade passage of a transonic axial compressor. Wernet (1998) also employed DPIV to obtain both time-averaged and instantaneous velocity maps in the diffuser region of a stable operating high speed centrifugal compressor.

A complete 2-D DPIV velocity mapping campaign in the diffuser region of a $431 \mathrm{~mm}$ diameter, 4:1 pressure ratio centrifugal compressor operating at stable conditions has recently been completed. The results will be used to augment previous surveys obtained using Laser Doppler Velocimetry (LDV) in both the diffuser and impeller regions, Skoch et al. (1997). The DPIV measurements have been obtained from 6 to 95percent span, which is closer to the diffuser hub 
than was possible using LDV. Both the DPIV and LDV data are being used to assist in computational fluid dynamics code validation. These DPIV measurements of the stable operating point of the compressor were used to generate time-averaged, phase stepped velocity vector maps. In this paper we present results from the simultaneous capture of instantaneous flow field data along with dynamic pressure measurements to diagnose the range of flow conditions experienced during surge.

Many researchers have investigated the area of active stall control in axial compressors. Paduano et al. (1993) demonstrated the first use of active stall control to increase the operating range of compressors by oscillating the inlet guide vanes in a low speed axial compressor. Day (1993) used pulsed air injection to successfully extend the operating range on a low speed axial compressor. Weigl et al. (1997) demonstrated the use of controlled air injection in a transonic axial compressor resulting in an extension of the surge margin by over 17 . The work of Oakes et al. (1999) on a low speed centrifugal compressor equipped with air injection for active stall control showed that rotating stall precursors occurring in the impeller region were largely responsible for the stall and surge cycle. Unsteady air injection was used to squelch the rotating stall events and lower the stalling mass flow of the compressor with minimal injection. Since active control strategies used at low speed may not be directly applicable in high speed compressors, due to compressible modes and the influence of the diffuser on surge and stall, it is not clear whether the approach used by Oakes et al. (1999) would be successful in a high speed centrifugal as well.

In all of these compressor stall and active stall control investigations, dynamic pressure data was primarily used to document the changes occurring in the compressor flow. Without detailed measurements of the flow, the use of dynamic pressure data restricts the researchers to a cause and effect analysis. The pressure characteristics are used to document the compressor behavior with and without stall control, and can be used only to infer what is actually happening in the flow and why one stall control approach has only a minimal effect while another has a more dramatic effect. In this work we demonstrate that DPIV is an invaluable tool for diagnosing the actual changes in the flow field during stall/surge events. Application of DPIV to active stall control studies should offer a wealth of insight into the actual mechanisms leading to stall and in the evaluation of the different stall control algorithms, and should therefore significantly reduce the time required to understand and implement an active stall control system. The next phase of this research investigation will utilize the information gained from the DPIV measurements to optimize the air injection locations for active stall control in the high speed centrifugal compressor.

\subsection{Compressor Facility, Optical Access and Light Sheet Delivery}

The centrifugal compressor is a Rolls Royce-Allison design that was scaled to a flow size of $4.54 \mathrm{~kg} / \mathrm{s}$ from the original size of $1.66 \mathrm{~kg} / \mathrm{s}$. The impeller and vaned diffuser were designed to produce a pressure ratio of $4: 1$ at the design mass flow. The standard day corrected speed for the design flow condition is $21,789 \mathrm{rpm}$ with an exit tip speed of $492 \mathrm{~m} / \mathrm{s}$. The inlet relative Mach numbers on the suction surface range from 0.9 at the tip to 0.45 at the hub. The absolute Mach number at the impeller exit is 0.87 . The impeller contains 15 main blades with 15 splitter blades and has 50 degrees of backsweep from radial at the discharge. The splitter blade leading edge, located at 30 percent of the main blade chord, is offset slightly toward the main blade suction surface to provide an even flow split. The inlet tip diameter is $210 \mathrm{~mm}$ and the inlet blade height 
is $64 \mathrm{~mm}$. The exit diameter is $431 \mathrm{~mm}$ and the exit blade height is $17 \mathrm{~mm}$. The vaned diffuser consists of 24 two-dimensional wedge vanes with the leading edges located at a radius ratio of 108 percent relative to the impeller exit. The diffuser has an overall area ratio of 2.75 with a total divergence angle of $7.8^{\circ}$. The diffuser exit radius is $363 \mathrm{~mm}$ and dumps directly into a $90^{\circ}$ annular bend. The nominal operating impeller exit clearance is $0.4 \mathrm{~mm}$, or 2.4 percent of the passage height at the exit. The static temperature at the diffuser throat is $108 \mathrm{C}$ based on the total temperature of $198{ }^{\circ} \mathrm{C}$, measured using thermocouples in the hub wall, and the PIV measured absolute flow velocity of $300 \mathrm{~m} / \mathrm{s}$. The compressor flow is subsonic under stable operating conditions where the absolute local speed of sound at the diffuser throat is $357 \mathrm{~m} / \mathrm{s}$ based the estimated static temperature. The compressor can be driven into stall by backpressuring the compressor via the collector valve. The compressor enters stall at a mass flow rate just below $4.26 \mathrm{~kg} / \mathrm{s}$.

A test-rig cross section showing the flow path through the impeller and diffuser can be seen in figure 1, while figure 2 shows a frontal view of the impeller and diffuser. The rig casing is designed to accept 4 separate window frame inserts, each containing a different set of windows with interspersed locations to provide access all along the flow path from the impeller entrance to the diffuser. Figure 1 shows two small diameter LDV optical access ports in the forward insert. The port located furthest upstream, which is denoted in figure 1, was used to obtain PIV measurements of the flow entering the impeller. The port is $25 \mathrm{~mm}$ in diameter and has a centerline location $25 \mathrm{~mm}$ upstream of the impeller leading edge. Most of the PIV data were obtained using the large window port $(70 \times 70 \mathrm{~mm})$ located over the impeller exit/diffuser section of the compressor, as shown in figures 1 and 2 . There is insufficient space near the compressor rig for the PIV CCD camera to view the illuminated flow passage directly. A mirror mounted at $45^{\circ}$ to the illumination plane is therefore used to provide the CCD recording camera with a view of the illuminated diffuser flow passages.

A compact light sheet delivery system was constructed using a periscope type configuration, as discussed by Wernet (1997). The pulsed Nd:YAG beam is directed down the bore of the tube which contains light sheet forming optics and a $45^{\circ}$ turning mirror. The periscope probe has an outside diameter of $12.7 \mathrm{~mm}$ and utilizes $8 \mathrm{~mm}$ diameter optics $(256 \mathrm{~mm}$ focal length spherical and $-102 \mathrm{~mm}$ focal length cylindrical lenses) to form the Nd:YAG laser beam into a laser sheet of approximately $13 \times 1 \mathrm{~mm}$. The distance from the probe to the measurement location is approximately $240 \mathrm{~mm}$. An articulated light arm with mirror joints was used to couple the beam from the Nd:YAG laser to the probe. Use of the light arm simplifies the coupling of the Nd:YAG beam to the periscope and also adds an increased level of safety to the installation since the beam is entirely enclosed when outside of the compressor casing. There is a tendency for the laser beam path to wander depending on the orientation of the light arm. Some care must be taken to ensure that the laser beam travels down the center of the light arm to properly couple light into the probe. The light sheet delivery probe has been successfully used to deliver $125 \mathrm{~mJ}$ pulsed illumination into the compressor passages. The light sheet exits the probe through a sealed window, which keeps the optics inside the probe protected from contamination by seed material.

The small diameter periscope probe is inserted through the compressor casing downstream of the diffuser vanes at the $90^{\circ}$ bend in the collector, as shown in figure 1. Five insertion holes were 
machined into the collector housing to permit illumination of four different diffuser vane passages. The four illuminated diffuser vane passages are successively higher in the optical viewport window, providing access to both the pressure and suction sides of the diffuser passages and the space between the exit of the impeller and the diffuser, see figure 2. Moving the probe in and out through the collector housing changes the spanwise location of the illumination plane. The insertion holes were machined so that approximately half of the probe diameter was recessed in the housing wall. These insertion locations ensure that the light sheet probe does not disturb the flow at the actual measurement location, nor does it choke the flow through the diffuser vanes.

The compressor casing was fitted with dynamic pressure transducers (three $340 \mathrm{kPa}$ and one $100 \mathrm{kPa}$ Kulite transducers) at four locations. The transducer circumferential locations are referenced in degrees from top-dead-center, proceeding in a clock-wise direction. The center of the optical access viewing port is located at $270^{\circ}$. The locations of the three $340 \mathrm{kPa}$ Kulite transducers are indicated in figure 2. Two transducers were located in the vaneless space between the impeller and the vaned diffuser (from 100 to 108 percent of the impeller radius). Transducer $\# 1$ was located at $343^{\circ}$ and $\# 2$ was located at $35^{\circ}$. Transducer \#3 was located in the diffuser throat at $43^{\circ}$ from top-dead-center. Transducer $\# 4$, a $100 \mathrm{kPa}$ Kulite which is not shown in figure 2, was located $25 \mathrm{~mm}$ upstream of the impeller at $338^{\circ}$ from top-dead-center, at the same axial location as the centerline of the forward most LDV optical access port shown in figure 1. Only four transducers were used during these initial measurements, due to the concern over seed particle contamination. However, no degradation of the dynamic pressure transducers resulting from the flow seeding has been observed in the course of this work.

In order to measure the incipient stalling mechanisms, dynamic pressure measurements of the stall precursors were collected in the centrifugal compressor facility before the DPIV measurements were obtained. Dynamic pressure data were collected over a matrix of mass flows and rotational speed combinations. The measurements were obtained around the circumference of the compressor from transducers mounted in the compressor casing ahead of the impeller, in the vaneless passage, and in the diffuser throat. These measurements illustrated that rotating stall cells travel at approximately 25 to 33 percent of the impeller rotational speed. Measurements also indicate that at 70 percent speed and below stall begins in the impeller region, whereas at design speed stall originates in the diffuser.

\subsection{Seeding}

Seeding the high temperature and high speed flow encountered in the diffuser is a challenging task. In a previous LDV velocity mapping program conducted in this centrifugal compressor facility, a seeding system was specifically designed to enable measurements in the high temperature flows encountered in the diffuser region, Skoch et al. (1997). Attempts to use PolyStyrene Latex spheres (PSL) failed due to the seed material collecting and then melting on the optical access ports. Instead a technique employing $\mathrm{pH}$ stabilized dispersions of alumina in ethanol was used, Wernet and Wernet (1994). The dispersions of alumina were injected into the facility via two commercial spray nozzles mounted in the plenum tank, approximately 10 meters upstream of the impeller. The specific gravity of the alumina powder is 3.96 and the particle size distribution has a mean of $0.7 \mu \mathrm{m}$ and a standard deviation of $0.2 \mu \mathrm{m}$. The concentration of 
alumina powder used in the dispersions was approximately 25 grams/liter. A side benefit of the alumina seeding is that it does not have a tendency to adhere to the optical access ports, permitting long rig run times without contamination of the view ports.

The frequency response and particle lag distance behind an oblique shock for various seed materials has been reported by Melling (1997). Using Melling's results, the seed particles used here would have a frequency response on the order of $3 \mathrm{kHz}$. The alumina particles have adequate flow following attributes for the flow field characteristics to be encountered in the stable operating point centrifugal compressor flow.

\subsection{Image Acquisition and Data Processing}

Electronic image acquisition based PIV has been demonstrated to provide adequate spatial resolution velocity measurements in the narrow flow passages encountered in turbomachinery. Another advantage of electronic image acquisition is near real-time feedback of the experimental parameters such as: laser pulse energy; seed particle concentration; assessment of flare light from blade surfaces and camera inter-exposure time. Use of a 1008x1016 pixel, "frame-straddling" CCD camera enables acquisition of single exposure image pairs which can be processed using the cross-correlation technique. Cross-correlation data reduction is the optimal data reduction technique for DPIV since it offers directionally resolved velocity vectors and the maximum dynamic range in the velocity measurements. The accuracy of the velocity estimates is inversely proportional to the particle displacement between exposures. The maximum displacement is restricted to $1 / 4$ of the correlation subregion size; hence using a correlation subregion size of $32 \times 32$ pixels yields a maximum measurable displacement of 8 pixels. The correlation peak location can nominally be estimated to within 0.1 pixels, yielding measurement errors on the order of 1 percent of full scale for $32 \times 32$ pixel subregion processing. For more details of the PIV technique, hardware and data reduction strategies see Raffel et al. (1998).

An electronic shaft angle encoder triggered from a once-per-rev signal on the impeller drive shaft was used to trigger image acquisition and laser firing, permitting DPIV data to be reliably recorded from a selected blade passage of the impeller under stable operating conditions. Increasing or decreasing the trigger delay time enabled collecting velocity vector maps at different impeller phasing positions relative to the diffuser vanes. The camera image acquisition and laser firing were all software controlled via a commercial synchronizer. The DPIV control and data acquisition computer was located next to the compressor rig. Remote operation was accomplished through the use of a commercial remote computer control box, which enables a remotely located monitor, keyboard and mouse to control the DPIV computer from the facility control room.

The image acquisition software used in the DPIV system enables acquisition of a single image frame pair or alternatively, a sequence of image frames. Efficient data acquisition was achieved by acquiring 100 frame sequences (50 frame pairs) into the computer's memory and saving them directly to the hard disk. Correlation processing of the images was performed off-line after the experiment was completed. Using the once-per-rev signal to trigger the DPIV system resulted in an image acquisition rate of approximately 8 frame pairs/sec. Images were written to the hard drive at the rate of 1 per second. 
The onset of compressor stall is a random event, which cannot be precisely predicted. Therefore, the DPIV sequence acquisition was initiated before the compressor went into surge, capturing images of the flow field during the evolution of stall precursors, rotating stall, and surge. PIV image data were asynchronously acquired throughout the full range of the stall/surge process. A separate computer was used to digitize the signals from the dynamic pressure transducers and the Nd:YAG laser Q-switch trigger signals. Triggering the Nd:YAG laser Q-switch produces the pulsed output. The Q-switches are only fired when image data is being acquired from the crosscorrelation CCD camera. The digitized laser Q-switch trigger and dynamic pressure signals were examined to determine when a PIV image pair acquisition coincided with the passage of a stall precursor or a surge event. This data acquisition strategy therefore enabled a posteri synchronization of the PIV data with the compressor stall events.

The commercial PIV system used to collect the data offers on-line data visualization capabilities that are extremely useful for optimizing the experiment parameters. However, the commercial system lacked some features necessary to expedite processing the large volumes (gigabytes) of data acquired in this measurement program. A custom Windows 95/NT application interface based cross-correlation data processing program was written to process the large volumes of data in batch mode, automating many steps that would otherwise have to be done manually. The FORTRAN based data reduction software incorporated left/right image reversal correction, image gain scaling, region of interest processing, fuzzy logic data validation and on-line graphical display of the velocity vector maps as they are processed, Wernet (1999).

\subsection{Results and Discussion}

\subsection{Light Sheet Probe and Flow Seeding}

The light sheet probe worked very well for providing the requisite $13 \times 1 \mathrm{~mm}$ light sheet with minimal scattering from the diffuser vanes and impeller. The light sheet probe was located in insertion port \#3 for all of the raw and processed DPIV image data shown in this work. The normal seed particle concentration obtained in the diffuser region was approximately 8 particles $/ \mathrm{mm}^{3}$. During compressor surge, the seed particle concentration in the diffuser increased by nearly an order of magnitude over the stable operating point seed concentration. A sample single exposure PIV image illustrating the very high concentration of seeding obtained during compressor surge is shown in figure 3. The diffuser vanes have been overdrawn in white to highlight their locations in the image. The impeller is also observed on the right side of the figure. The alumina powder did not adhere to the glass surfaces, as was observed by the lack of seed material buildup on the optical access port window and light sheet probe exit window. The optical access port and probe exit window only remained clean if the seeder was turned on after the compressor was operated at its design speed long enough for the casing temperature to reach thermal equilibrium. At design conditions the tip clearance gap is $0.4 \mathrm{~mm}$ and the compressor casing temperature near the diffuser reaches $175^{\circ} \mathrm{C}$. If the seeder was turned on at less than design speed then the optical access ports became coated with seed material in a matter of seconds. Hence, the seeder was only operated after the compressor had reached design speed and thermal equilibrium. 


\subsection{Anatomy of Compressor Surge}

The compressor was operated just above stall at approximately $4.26 \mathrm{~kg} / \mathrm{s}$ mass flow and $21,750 \mathrm{rpm}$. The camera field of view for the DPIV measurements was approximately $61 \times 61 \mathrm{~mm}$, yielding a spatial resolution of $61 \mu \mathrm{m} / \mathrm{pixel}$. Image frame pairs were acquired with an intra-frame time of $1.8 \mu \mathrm{s}$. The data were processed using $64 \times 64$ pixel sub-regions, subregion image shifting and with 75 percent overlap to ensure that high quality velocity vector maps with minimal data dropout were obtained. Particle image displacements ranged from 0 to over 16 pixels for the data presented here. Velocity measurements were obtained at 12, 30, 50, 90 and 95 percent span ( 0 percent span is at the hub, while 100 percent span is at the casing) on both the suction and pressure sides of the diffuser channel.

The compressor was driven into stall by restricting the flow in the compressor via the downstream collector valve. After the compressor entered stall the collector valve was then reopened to allow the compressor to recover. Approximately 3-5 surge cycles occurred between entering and exiting surge. As described above, the dynamic pressure transducer measurements were used to reconcile the acquired DPIV image data with the time evolution of the rotating stall and surge events. Both the laser Q-switch trigger signals and pressure transducer signals were digitized at a $3 \mathrm{kHz}$ sampling rate for a period of 15 seconds. The DPIV image sequence acquisition lasted about 10 seconds. The data were acquired by first starting the pressure signal digitization. Then the DPIV image sequence acquisition was initiated (this ensured that the DPIV data was contained within the 15 second pressure data record). While these measurements were being acquired, the collector valve was closed down, driving the compressor into surge.

A section of the digitized signals from the laser Q-switch trigger and the \#3 pressure transducer signal (located in the diffuser throat region) are shown in figure 4. DPIV image acquisition and Kulite signal digitization both preceded and followed the surge events. The spiked signals represent the laser Q-switch trigger pulses, and hence pulsed laser output. The observed spacing between laser firings is slightly irregular, since the once-per-rev signal from the compressor was used to initiate the laser firing. The compressor surge events are illustrated by the large high to low pressure fluctuations observed in the data. Surge events were differentiated from rotating stall by the simultaneous occurrence of large high to low pressure fluctuations on all three dynamic pressure transducers located in the diffuser. The stable operating point pressure in the diffuser throat was approximately $280 \mathrm{kPa}$ and the observed surge fluctuations contained peak pressure levels of $540 \mathrm{kPa}$ and minimum pressure readings of $170 \mathrm{kPa}$. Each surge cycle consists of an initial large spike in pressure in the diffuser. The increasing backpressure caused by closing down the collector valve decreases the mass flow, which results in flow separation on both the pressure and suction sides of the diffuser passage. As will be shown in the discussion below, an indication of low momentum fluid on the pressure side of the passage is observed at the bottom portion of the velocity vector plot in figure $5 \mathrm{~A}$. Other velocity vector data (not shown here) obtained using optical insertion port \#2 revealed an even larger low momentum region on the suction side of the diffuser passage. The low momentum flow on both sides of the passage reduces the effective flow area in the diffuser. The impeller pumps against the blockage that develops in the diffuser, which we believe leads to the large rise in pressure at the start of the surge event. The pressure in the diffuser increases until the impeller can no longer work against the developed head. At this point the high pressure fluid in the diffuser rushes back upstream into the vaneless space, resulting in a 
sharp drop in pressure in the diffuser. The pressure then slowly recovers from the minimum value back to the stable operating point pressure level before the next surge cycle begins. The frequency of the surge cycles is approximately $3 \mathrm{~Hz}$. The impeller makes roughly 100 revolutions during each surge cycle. The stable operating pressure level before the surge event is higher than the pressure level following surge since the collector valve has been opened up wider than the pre-stall position to allow quick recovery. An indication of rotating stall in the pressure trace shown in figure 4 is observed in the steadily increasing amplitude of the sinusoidal variation of the pressure readings just prior to the first surge cycle. The frequency of the rotating stall cells is approximately $29 \mathrm{~Hz}$. The lifetime of the rotating stall cells is directly influenced by the rate at which the collector valve is closed. Our goal was to capture both rotating stall and surge events within the 10 second PIV system data acquisition window. As a result, not much rotating stall information prior to the onset of surge is contained in the pressure data.

The dynamic pressure transducer data enabled the DPIV measurements to be reconciled with the surge events passing through the DPIV measurement location. Our collection of PIV measurements over hundreds of surge cycles indicate that the flow features measured during the surge cycles are repeatable with respect to the time of occurrence within the surge cycle. Figure 5 shows a surge cycle pressure fluctuation and four processed DPIV velocity vector maps. The four velocity vector maps in figure 5 are from different surge cycles. A representative dynamic pressure trace is shown at the top of figure 5 where four laser Q-switch trigger pulses are also displayed. The four spikes (labeled A, B, C, and D) mark the relative location of the PIV image acquisitions during the surge event. The independent PIV velocity fields have been referenced onto this representative pressure trace using the pressure minimum of the individual pressure trace data for the independent surge cycles as a common timing reference point. In the velocity vector plots, the $\mathrm{x}$-direction corresponds primarily to the compressor radial coordinate, while the y-direction corresponds primarily to the circumferential compressor coordinate. The black velocity vectors are overlaid on a color contour plot of the velocity vector magnitudes, which enhances the changes in flow magnitude. The impeller wheel and blades are shown on the right side of the plots, along with a reference vector near the top of the plots. The image synchronization technique breaks down during the surge event since the radical changes in compressor loading cause deviations in the rotational speed of the impeller, which also affects the triggering of the DPIV system. The loss of synchronization is manifested in the impeller blades being captured at random positions. Figure $5 \mathrm{~A}$ shows the velocity field at a stable operating mass flow just above surge at 90 percent span. At this stable operating condition just above surge, the high speed flow outside of the diffuser is observed to slow significantly as it enters the diffuser, indicating that diffuser stall is eminent. At the bottom of figure 5A we observe that the low momentum flow that develops from both the suction and pressure sides of the diffuser passage has grown large enough to span the full passage width. As mentioned above, we believe that this low momentum fluid provides the blockage that results in the sharp pressure rise at the start of the surge cycle.

The impeller builds pressure against the blockage in the diffuser until the impeller can no longer pump against the developed head. At this point in the surge cycle, the high pressure fluid built up in the diffuser flows back upstream into the vaneless space. Two main factors influence the characteristics of the reversing flow. During backflow, the diffuser vane passage acts as a 1-D nozzle. In the absence of the impeller and with a steady-state $\Delta \mathrm{P}$ from diffuser throat to exit, we 
would expect to see an accelerating flow in the diffuser vane passage with the maximum velocity occurring at the throat of the diffuser. However, the pressure gradient along the diffuser passage is changing with time, therefore, the magnitude of the reversing flow will be a function of the driving pressure gradient in the diffuser, which is in turn a function of time (or where we are in the surge cycle). Secondly, the backflowing fluid appears to occur in waves or packets. These packets are best described as transitions from low to high velocity within the diffuser. The high velocity packet fronts appeared to be correlated with the passing impeller blade positions. Potential pressure fields emanate from the impeller blades. They also can be generated at the diffuser vane leading edge due to the high incidence angles that occur during surge. The strength of these potential pressure fields (which will be referred to here as pressure waves) drops off exponentially away from the blades. These pressure waves appear to interact with the backflowing fluid in the diffuser. The character of the reversing flow exiting the diffuser is influenced by the relative orientation of the impeller blades and hence the pressure waves relative to the diffuser vane leading edge. In the data shown below, we are able to identify the time of the PIV image acquisitions with respect to the time dependent pressure gradient along the diffuser; however, the impeller is still captured at random orientations relative to the diffuser vane leading edge.

The velocity data shown in figures 5B-D was obtained at 95 percent span. In order to enhance the details of the lower dynamic range flow, the color scale and vector magnitudes in figures $5 \mathrm{~B}-\mathrm{D}$ is different from the data in figure 5A. Figure $5 \mathrm{~B}$ shows the flow field corresponding to the highest pressure condition in the diffuser, where the packet velocities range from 50 to $225 \mathrm{~m} / \mathrm{s}$. Under these conditions, the highest velocity flow (denoted by red/pink region) is observed just at the diffuser throat. Flare light around the diffuser vane leading edge is the source of the data dropout in the leading edge region. The flow is observed to turn sharply as it clears the diffuser vane leading edge and flow up into the vaneless space. Two impeller blades are observed in this figure. The pressure wave from the upper blade is seen to be encroaching on the high velocity fluid exiting the diffuser and a complete flow reversal is observed just behind the upper blade's pressure wave. The lower blade is also observed to have an effect on the flow deep into the diffuser. The high velocity front of the lower fluid packet in the diffuser appears to be correlated with the lower blade position.

In figure $5 \mathrm{C}$, the pressure trace data indicates that the DPIV image data were acquired on the falling edge of the high pressure spike, at a point roughly equal to the stable operating point pressure level. The pressure gradient driving the flow is smaller than in the case of the flow shown in figure $5 \mathrm{~B}$. The processed velocity vector map shows moderate velocity fluid packets, 30 to $150 \mathrm{~m} / \mathrm{s}$, and the phase fronts of the fluid packets (orange/yellow region) are still correlated with the impeller blade locations. Again the flow is observed to turn sharply as it clears the diffuser vane and flow up into the vaneless space. In this image, the impeller blade is below the vane tip and the flow is leisurely turning into the vaneless space. Recall that the characteristics of the instantaneous flow field are influenced by the relative strength of the pressure gradient along the diffuser and the impeller circumferential orientation at the time of the PIV image acquisition. Therefore, each instantaneous velocity vector map will be unique unless the instantaneous pressure gradient along the diffuser and impeller orientation are identical, which is not the case for any of the data presented here. 
Figure 5D shows the backflowing condition near the end of the high pressure spike, just before the pressure in the diffuser makes the sharp drop to its lowest point. At this point in the surge event it appears that the pressure gradient driving the reverse flow has reached equilibrium with the head developed by the impeller. Here we see that in each fluid packet the flow velocity starts out at approximately $0 \mathrm{~m} / \mathrm{s}$ and accelerates up to about $70 \mathrm{~m} / \mathrm{s}$. The high velocity front of the fluid packet is aligned with the pressure surface of the impeller blade. The fluid exiting the diffuser turns sharply to the right and flows into the constricted region of the vaneless space defined by the pressure wave from the upper blade and the vane leading edge. The fluid packet corresponding to the lower blade is slightly lagging behind the blade. These reverse flow vector plots represent the general character of the over 100 DPIV image frames that were acquired depicting backflow in the diffuser passage. Additional DPIV measurements at 12, 30 and 50 percent span during compressor surge verified that the backflow condition shown here spans the entire diffuser vane passage from hub to tip. Therefore, the 90 and 95 percent span data shown here in figures 5 and 6 are generally representative of the full passage reversing flow field during surge.

Figure 6 shows the surge cycle pressure fluctuation and four processed DPIV velocity vector maps acquired at 90 percent span as the compressor recovers from surge. The four velocity vector maps are again from different data sets, combined here to illustrate the evolution of the flow during the low pressure portion of the surge cycle. The four spikes (labeled E, F, G, and H) in the pressure data plot mark the relative location of the image acquisitions during recovery from the surge event. Note that the velocity scales in figures $6 \mathrm{E}-\mathrm{F}$ are different than those in figures $6 \mathrm{G}-\mathrm{H}$ to again better accentuate the flow features. As shown by the results in figure 5, the backflow condition appears to last in the diffuser until the pressure reaches the point marked by laser pulse $\mathrm{E}$ in figure 6. Prior to this point the pressure has been gradually falling in the diffuser. However, at laser pulse E we observe an almost instantaneous $70 \mathrm{kPa}$ drop in pressure. At this point in the surge cycle forward flow appears to reestablish in the diffuser.

Figure $6 \mathrm{E}$ shows the velocity field at laser firing pulse $\mathrm{E}$, corresponding to the point just prior to the minimum in pressure in the diffuser. The sharp drop in pressure causes a rush of air to flow into the diffuser. As shown in the velocity vector map, the diffuser throat acts as a convergent/divergent nozzle and supersonic flow with velocities on the order of $550 \mathrm{~m} / \mathrm{s}$ (corresponding to an absolute Mach number of 1.5) is obtained within the diffuser. Although this Mach number is based on the stable operating point temperature in the diffuser throat, any temperature variations during surge would have minimal impact on the local Mach number. Just below the supersonic shock front a region of nearly stagnated flow is observed (indicated by the blue/green region). This stagnated region is the last remnant of the reversed flow shown in figure $5 \mathrm{D}$, which occurs near the end of the high pressure portion of the surge cycle. The existence of the low momentum flow (region of irregular seeding) is readily observed on the pressure side of the diffuser passage in the raw DPIV image shown in figure 3. The apparent lack of seed in this stagnated region lends further evidence that this is low pressure air (hence low density and low seed particle concentration) left over from the reverse flow state.

Figure $6 \mathrm{~F}$ shows the highest velocity flow that was observed during the low pressure condition in the diffuser. The DPIV image acquisition corresponds to the laser Q-switch trigger pulse F indicated in the pressure trace plot at the top of figure 6. The location of the laser Q-switch trigger 
pulse relative to the Kulite \#3 signal shows that the DPIV image pair has been acquired a short time after the lowest pressure was recorded at the diffuser throat. The maximum velocity achieved at this condition was $625 \mathrm{~m} / \mathrm{s}$, corresponding to an absolute flow Mach number of 1.7. The relatively uniform flow outside of the diffuser steadily accelerates as it enters the diffuser throat. The propagation of the shock front (pink colored region) is readily observed just above the low velocity flow region (green/yellow region). Figure $6 \mathrm{~F}$ shows the last remnants of the low velocity region in the diffuser (near the bottom of the image). This region is smaller and further down in the diffuser than in the velocity field shown in figure $6 \mathrm{E}$. Figures $6 \mathrm{E}-\mathrm{H}$ illustrates the start of the process which reestablishes forward flow and pressure recovery within the diffuser prior to the next surge cycle.

Figures $6 \mathrm{G}$ and $\mathrm{H}$ show the velocity field in the diffuser as the pressure continues to recover from the minimum level. This gradual pressure rise is the longest portion of the surge cycle. Figure 6G corresponds to the point where the pressure has recovered from the pressure minima to approximately 80 percent of the stable operating point value and shows a region of high speed flow still down inside the diffuser. The flow in the diffuser is no longer supersonic, but is relaxing back to the stable operating point conditions as the pressure recovers. Figure $6 \mathrm{H}$ shows the flow field when the pressure has recovered to nearly the stable operation level. In this vector plot the flow closely resembles the stable operating point flow shown in figure 5A, where the high speed flow is mostly outside of the diffuser. The collection of velocity vector plots in figures 5 and 6 describe the changes in the flow occurring within a single surge cycle in the diffuser of this centrifugal compressor. The plots in figure 6 were obtained at 90 percent span, and in general depict the flow features occurring during the last half of the surge cycle. Future efforts will be devoted to examining the reestablishing flow in the diffuser at more span locations in order to identify more subtle variations in the flow.

We have no conclusive evidence that the flow reversing in the diffuser flows all the way out through the front of the impeller. The data shown here on the pressure side of the diffuser passage does not actually show the reversed flow going up through the impeller. Other PIV data collected on the suction side of the diffuser passage (which is not shown here) shows that during surge, the reverse flow propagates into the vaneless space towards the impeller, but not actually into the impeller. The lack of conclusive evidence of the flow reversing through the impeller may only be the result of not capturing the surge flow at the right instant in time.

We have several pieces of evidence that may lead us to believe that the fluid from the diffuser may actually reverse all the way up and out of the impeller. Evidence of flow reversal at the front of the impeller is given in figure 7. Here we have plotted static pressure data from Kulites \#3 (in the diffuser throat) and \#4 (at the impeller inlet) during several surge cycles. The pressure traces show that a pressure disturbance is detected at the impeller inlet a short time $(10 \mathrm{~ms})$ after the pressure spike is observed in the diffuser. The static pressure rise at the inlet (peaking at approximately $120 \mathrm{kPa}$ ) is higher than the stable operating point plenum static pressure of $83 \mathrm{kPa}$, which indicates that fluid is being expelled out of the impeller during surge. The inlet total pressure into the impeller is atmospheric, or $100 \mathrm{kPa}$. If the flow exiting the impeller were to be suddenly stopped (as in the case of the blockage that occurs during surge) then the pressure at the inlet would not be expected to exceed $100 \mathrm{kPa}$. However, the measured peak static pressure of 
$120 \mathrm{kPa}$ at the inlet during surge indicates that the high pressure fluid that built up in the diffuser must have expanded back out through the impeller. Note that the pressure disturbance at the inlet terminates, indicating a return to stable operating point flow conditions, when the pressure in the diffuser reaches a minimum.

A second compelling indication of full flow reversal was obtained by taking additional PIV measurements upstream of the impeller. A small LDV optical access port in the casing, which can be seen in figure 1, enabled PIV image data to be obtained $25 \mathrm{~mm}$ upstream from the impeller at 10 percent span. The light sheet was introduced via a removable casing plug located $180^{\circ}$ from top dead center. The stable operating point seed particle concentration upstream of the impeller is very low (6 particles $/ \mathrm{mm}^{3}$ ) compared to the concentration in the high pressure diffuser region, but still sufficient to obtain correlation results. The PIV measurement results are shown in figure 8, where the measured flow region is small $(28 \times 28 \mathrm{~mm})$ due to the $25 \mathrm{~mm}$ diameter optical access port. The blade profiles and spacing at the measurement plane are shown on the left side of the plots and the velocity data are shown in the absolute reference frame. The horizontal axis corresponds to the axial position upstream of the impeller and the vertical axis corresponds to the radial position relative to the impeller centerline. The flow is from right to left and the impeller is rotating from top to bottom. A reference vector is shown in the plots along with the axial location of Kulite \#4. The PIV data in figure 8a show a uniform $105 \mathrm{~m} / \mathrm{s}$ flow entering the impeller under stable operating conditions. The region of missing velocity vectors is due to flare light from the impeller centerbody. During a surge event, as the pressure starts to rise in the impeller inlet, the low seed concentration flow slows and starts to turn in the direction of rotation of the impeller. As the pressure peaks in the inlet, the flow reverses out of the impeller and moves tangentially with the impeller, as depicted in figure $8 \mathrm{~b}$. The magnitude of the reversing flow at this condition is approximately $50 \mathrm{~m} / \mathrm{s}$. The fluid reversing out of the impeller contains a factor of 5 more seed particles (33 particles $/ \mathrm{mm}^{3}$ ) than the stable operating point flow entering the impeller, which agrees with the high seed concentration observed in the diffuser region during the reverse flow condition. This suggests that the fluid coming out of the impeller originates in the diffuser, not in the impeller. After the flow reversal there appears to be a brief period where the flow moves in a direction opposite the impeller rotation direction. At this point we cannot offer an explanation for this phenomena, but it has been measured on several occasions. After this counter-rotating flow is observed, the flow quickly resumes the uniform stable operating point flow profile.

The $3 \mathrm{kHz}$ sampling rate used to digitize the signals from the Kulites is insufficient to prove that the pressure waves from the impeller blades are correlated with the fluid packets observed in the diffuser. The highest sampling rate at which the Kulite signals could be digitized with the computer based A/D board was $10 \mathrm{kHz}$. The minimum sampling rate to avoid aliasing of pressure disturbances phase locked to the impeller blade passing frequency of $10,875 \mathrm{~Hz}$ would be at least $22 \mathrm{kHz}$. A high speed digital storage oscilloscope was therefore used to record a pressure surge cycle from Kulite \#3 at a sampling rate of $25 \mathrm{kHz}$. The recorded Kulite signal showed a high frequency oscillation (on the order of $10.8 \mathrm{kHz}$ ) on top of the low frequency surge waveform. These high frequency oscillations confirm that the pressure waves from the blades are strong enough to significantly impact the character of the reversing flow during the high to low pressure transition portion of the surge cycle. We therefore believe that the observed wave packets within the reversing flow originate from the interaction of the pressure waves and the reversing flow. 
The computer based A/D system was then used to digitize the signals from Kulite \#3 at $10 \mathrm{kHz}$. The data are obviously aliased, but we have the information from the digital oscilloscope to confirm the actual frequency of the blade wakes. The $10 \mathrm{kHz}$ sampled Kulite signal is shown in figure 9. Figure 9a shows a series of surge cycles. Figure $9 \mathrm{~b}$ shows an expanded region of the pressure measurements (region outlined by dashed box) from $\mathrm{T}=3.8$ to 3.9 seconds, or one surge cycle. The data clearly show the presence of the pressure waves on the rising and falling edges of the high pressure portion of the surge cycle. Hence, the influence of the pressure waves only appears to be significant during the period of reverse flow in the diffuser. Although no valid frequency information can be gleaned from these measurements, the amplitude of the pressure fluctuations is observed to be roughly $\pm 35 \mathrm{kPa}$ during the high to low pressure transition of the surge cycle. These pressure fluctuations essentially disappear at the pressure minimum of the surge cycle, which appears to be the point where forward flow is reestablished in the diffuser.

\subsection{Conclusions}

Successful DPIV measurements have been obtained in a high speed centrifugal compressor yielding instantaneous snapshots of the complex flow fields occurring during compressor surge. High frequency response pressure transducer signals were used to reconcile the DPIV image data with the evolution of the compressor surge event. Light sheet illumination was obtained by inserting a light sheet generating probe through the collector housing downstream of the measurement location. Global seeding of the flow with alumina yielded sufficiently high seed particle concentrations to support correlation data reduction. Seed material contamination of the optical access port and light sheet generating probe was not significant.

Previous investigations of surge in compressors had to rely only on dynamic pressure data as an indicator of the flow conditions within the compressor. DPIV has been shown to be a remarkably powerful technique for capturing instantaneous flow field phenomena, enabling a study of the time evolution of flow variations occurring during the compressor surge cycle. The dynamic pressure data illustrate that a typical surge event consists of high pressure spike followed by a sharp drop in pressure and then a slow recovery back to the stable operating point pressure. DPIV measurements indicate that a significant low momentum fluid blockage develops in the diffuser at a stable operating point just above the stalling mass flow. With a further constriction of the mass flow, the blockage in the diffuser appears to cause the large pressure spike observed at the start of the surge cycle. Furthermore, the DPIV measurements show that at the peak of the high pressure spike, the flow in the diffuser completely reverses and flows up into the vaneless space, indicating a failure of the impeller to maintain the developed head. At the point of minimum pressure in the diffuser, forward flow is reestablished in the form of a supersonic shock front that propagates back down through the diffuser. The supersonic shock front forces the remnants of the reversing flow out of the diffuser. As the pressure slowly recovers in the diffuser, the high speed flow subsides and the flow field approaches the stable operating point conditions of high speed flow entering the diffuser and low speed flow within the diffuser. High seed particle concentration flow was noted to occur in the diffuser during the period of reverse flow. High seed particle concentration fluid is also observed to exit the front of the impeller during surge. PIV measurements also showed reverse flow exiting the impeller inlet. We cannot conclusively say 
that full flow reversal occurs throughout the diffuser/impeller, but the evidence compels us to believe that it may be possible. The DPIV image data also indicates that the reverse flow occurring during compressor surge is influenced by the pressure waves emanating from the passing impeller blades. After the DPIV data alerted us to the existence of the pressure waves influencing the reversing flow, high frequency dynamic pressure data were collected which confirmed that $\pm 34 \mathrm{kPa}$ pressure fluctuations are caused by pressure waves emanating from the impeller blades. These pressure waves in turn cause the wave packets observed in the reversing flow within the diffuser.

Combined DPIV and transient pressure measurements are helping us to understand pre-stall and pre-surge phenomena occurring in the compressor. In the data presented here, the compressor was quickly transitioned into surge within the DPIV image acquisition window, which did not allow for significant data acquisition during stall inception processes. Our future work will concentrate on operating the compressor in a sustained rotating stall condition during which DPIV data will be obtained. These measurements will concentrate on the precursive events that grow into large amplitude rotating stall and surge. Flow measurements of the stall precursors should significantly contribute to our understanding of the mechanisms leading up to compressor surge. Both the stable operating and unstable operating flow field data obtained in this work will be used to optimize the location of air injection ports for active control of rotating stall and surge. The ultimate goal of this work is the successful stabilization of the compressor for operation beyond its normal surge limit. Active stall control allows the compressor to achieve peak performance while maintaining adequate surge margin. Successful measurement and analysis of the stalling flow is the first step towards achieving this goal.

\subsection{References}

Bryanston-Cross, P. J., Towers, C. E., Judge, T. R., Towers, D. P., Harasgama, S. P., Hopwood, S. T., 1992, "The Application of Particle Image Velocimetry (PIV) in a Short-Duration Transonic Annular Turbine Cascade”, ASME Journal of Turbomachinery, Vol. 114, pp. 504--509, April.

Bryanston-Cross, P. J., Burnnett, M., Lee, W. K., Udrea, D. D., Chana, K., Anderson, S. J., 1997, "Transonic PIV (Particle Image Velocimetry) Measurements Made in The Stator Trailing Edge and Rotor Region of the ILPF (Isentropic Light Piston Facility) at Pyestock Farnborough", SPIE Conference on Optical Diagnostics in Fluid and Thermal Flow, Vol. 3172, pp. 561--574.

Day, I. J., 1993, "Stall Inception in Axial Flow Compressors," ASME Journal of Turbomachinery, Vol. 115, No. 1, January.

Gogineni, S., Goss, L., Copenhaver, W., Gorrell, S., 1998, "Development of Digital Two-Color PIV for Turbomachinery Applications", AIAA 35 th Aerospace Sciences Meeting, AIAA-97-0494, January 6-10, Reno NV.

Melling, A., 1997, “Tracer Particles and Seeding for Particle Image Velocimetry”, Meas Sci and Tech, Vol. 8, pp. 1406--1416. 
Oakes, W. C., Lawless, P. B., Fleeter, S., 1999, "Characterization of the Behavior of a Centrifugal Compressor with Active Stall Control", to be published in AIAA Journal of Propulsion and Power.

Oldenburg, M. and Pap, E., 1996, "Velocity Measurement in the Impeller and in the Volute of a Centrifugal Pump by Particle Image Displacement Velocimetry", Eighth International Symposium on Applications of Laser Techniques to Fluid Mechanics, Lisbon, Portugal, pp. 8.2.1-8.2.5, July 8-11.

Paduano, J. D., Epstein, A.H., Valavani, L., Longley, J. P., Greitzer, E. M., and Guenette, G. R., 1993, "Active Control of Rotating Stall in a Low Speed Axial Compressor", ASME Journal of Turbomachinery, Vol. 115, January.

Paone, N., Riethmuller, M. L., Van den Braembussche, R. A., 1988, “Application of Particle Image Displacement Velocimetry to a Centrifugal Pump", Fourth International Symposium on Applications of Laser Techniques to Fluid Mechanics, Lisbon, Portugal, pp 6, July 11-14.

Raffel, M., Willert, C., Kompenhans, J., 1998 Particle Image Velocimetry, A Practical Guide, Springer, New York.

Rothlübbers, C., Scheffler, T., Orglmeister, R., Siekmann, H., 1996, "Particle Tracking Velocimetry Measurements in a Radial Pump with Particle Pair Detection Using the Hough Transform", Eighth International Symposium on Applications of Laser Techniques to Fluid Mechanics, Lisbon, Portugal, pp 8.6.1-8.6.6, July 8-11.

Skoch, G. J., Prahst, P. S., Wernet, M. P., Wood, J. R., Strazisar, A. J., 1997 "Laser Anemometer Measurements Of The Flow Field In A 4:1 Pressure Ratio Centrifugal Impeller", ASME paper 97-GT-342.

Treml, K. D., Lawless, P. B., 1998, "Particle Image Velocimetry of Vane-Rotor Interaction in a Turbine Stage", AIAA-98-3599, 34 ${ }^{\text {th }}$ Joint Propulsion Conference, Cleveland, OH, July 13-15.

Weigl, H. J., Paduano, J. D., Frechette, L. G., Epstein, A. H., Greitzer, E. M., Bright, M. M., and Strazisar, A. J., 1997, "Active Stabilization of Rotating Stall and Surge in a Transonic Single Stage Axial Compressor”, ASME Paper No. 97-GT-411, June.

Wernet, J. H. and Wernet, M. P., 1994, "Stabilized Alumina/Ethanol Colloidal Dispersion for Seeding High Temperature Air Flows", Proceedings of the ASME Symposium on Laser Anemometry: Advances and Applications, Lake Tahoe, NV, June 19-23.

Wernet, M. P., 1997, "Demonstration of PIV in a Transonic Compressor", Proceedings of the AGARD $90^{\text {th }}$ Symposium on Nonintrusive Measurement Techniques for Propulsion Engines, Brussels, Belgium, October 20-24. 
Wernet, M. P., 1998, "Digital PIV Measurements in the Diffuser of a High Speed Centrifugal Compressor", AIAA-98-2777, Advanced Measurement and Ground Testing Technology Conference, Albuquerque, NM, June 15-18.

Wernet, M. P., 1999, "Fuzzy Logic Enhanced Digital PIV Processing Software", $18^{\text {th }}$ International Congress on Instrumentation for Aerospace Simulation Facilities (ICIASF), Toulouse, France, pp. 2.1 - 2.10, June 14-17. 


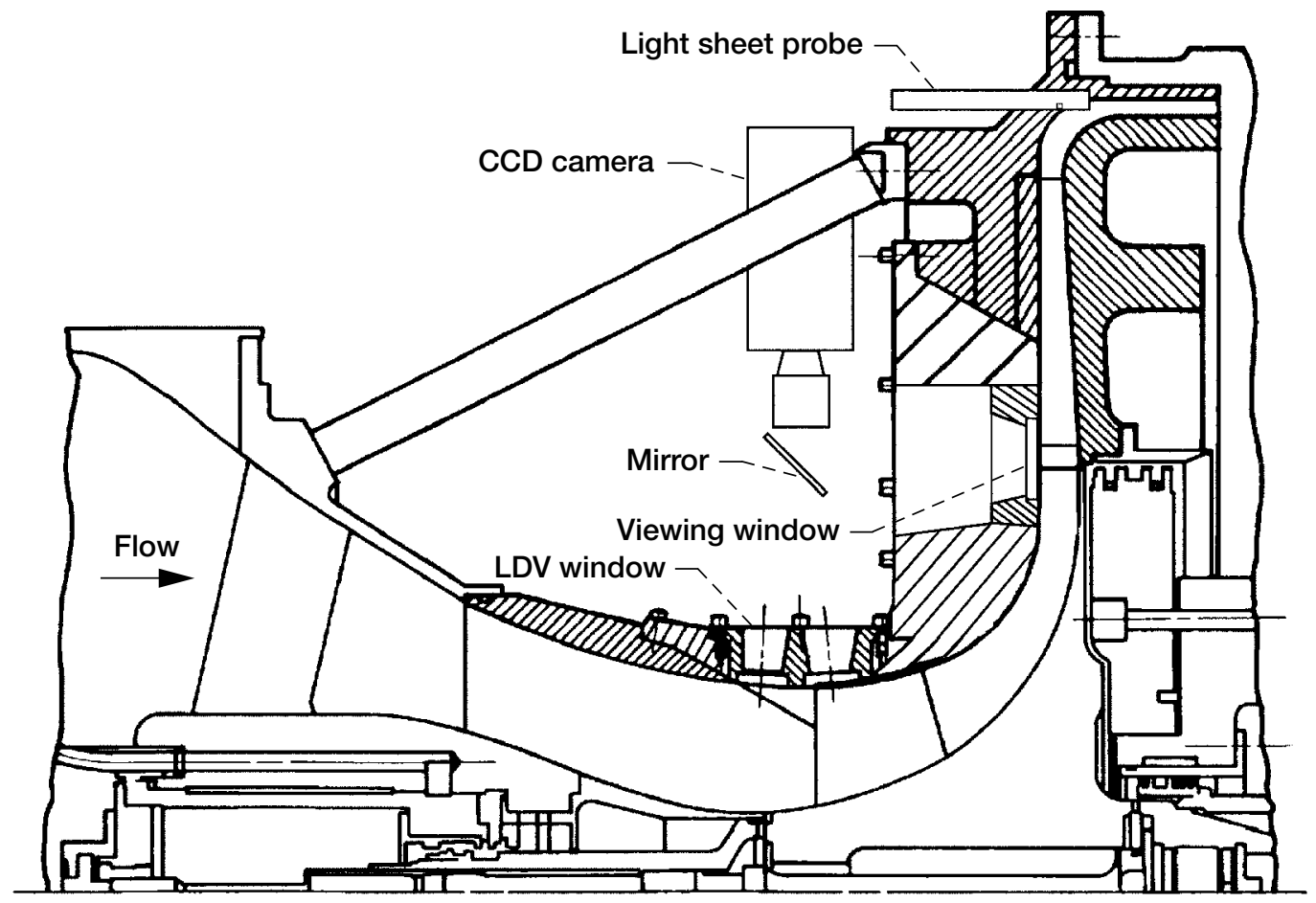

Figure 1.-Schematic cross section of centrifugal compressor facility. Optical access port and CCD camera mounting configuration are shown. Light sheet insertion and recession into compressor casing are also illustrated.

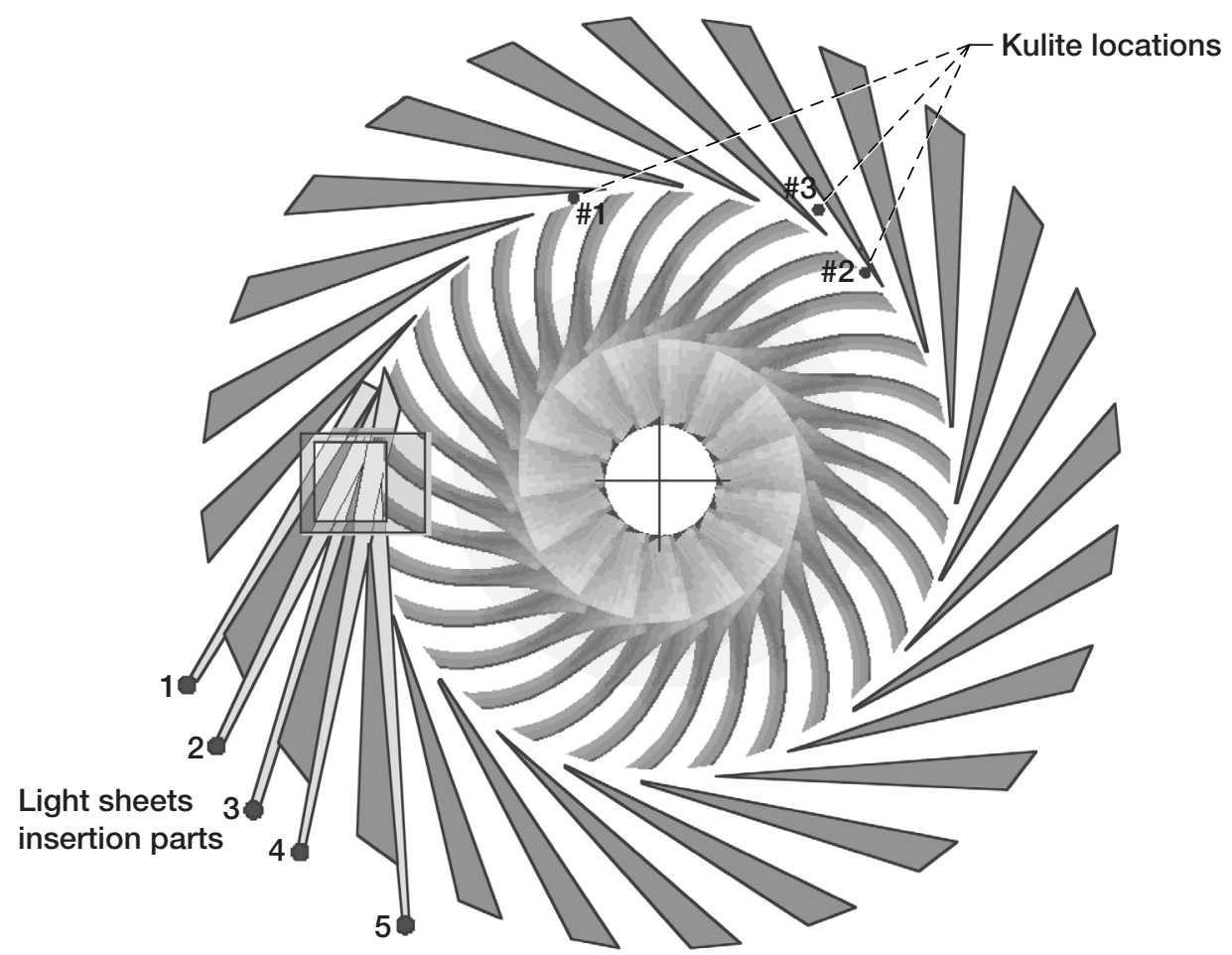

Figure 2.-Schematic drawing of vaned diffuser and impeller showing the optical viewing port, light sheet probe insertion locations, light sheet extents and Kulite locations. 


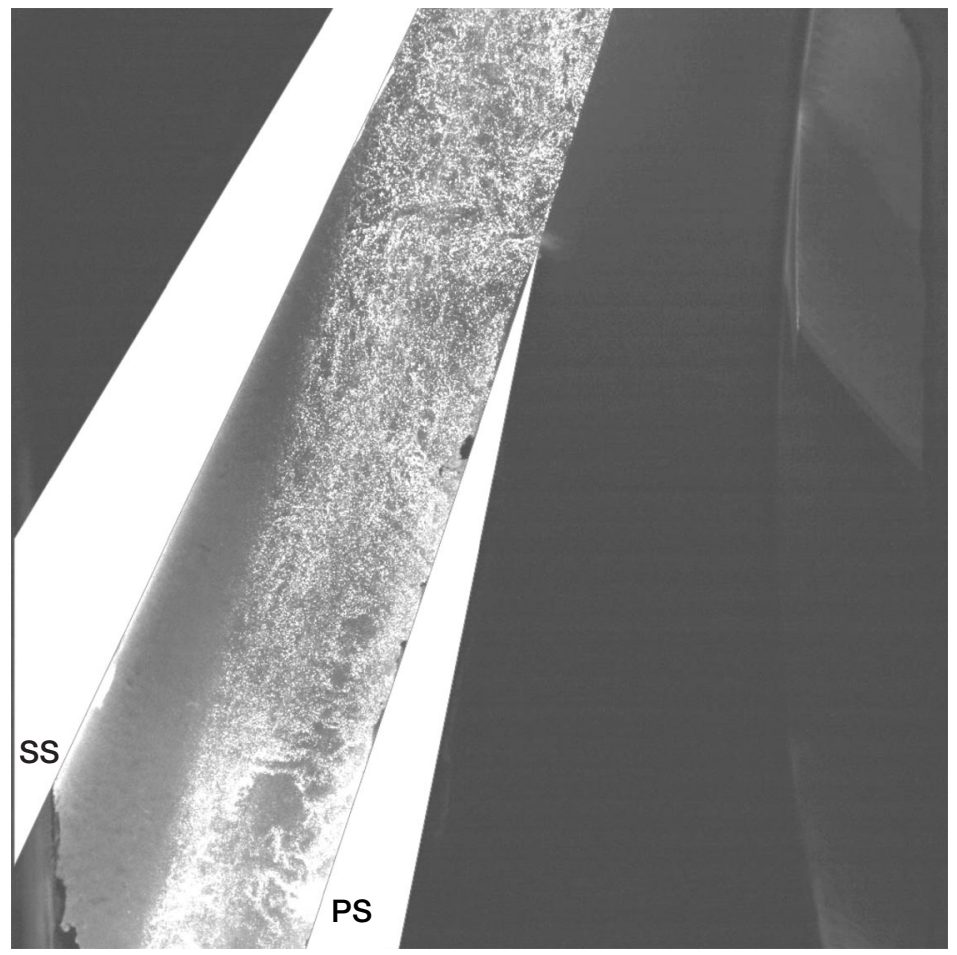

Figure 3.-Sample single exposure DPIV image obtained from the centrifugal compressor rig. The diffuser vanes have been overdrawn on the image to accentuate their extents and the pressure (PS) and suction surfaces (SS) have been labeled.

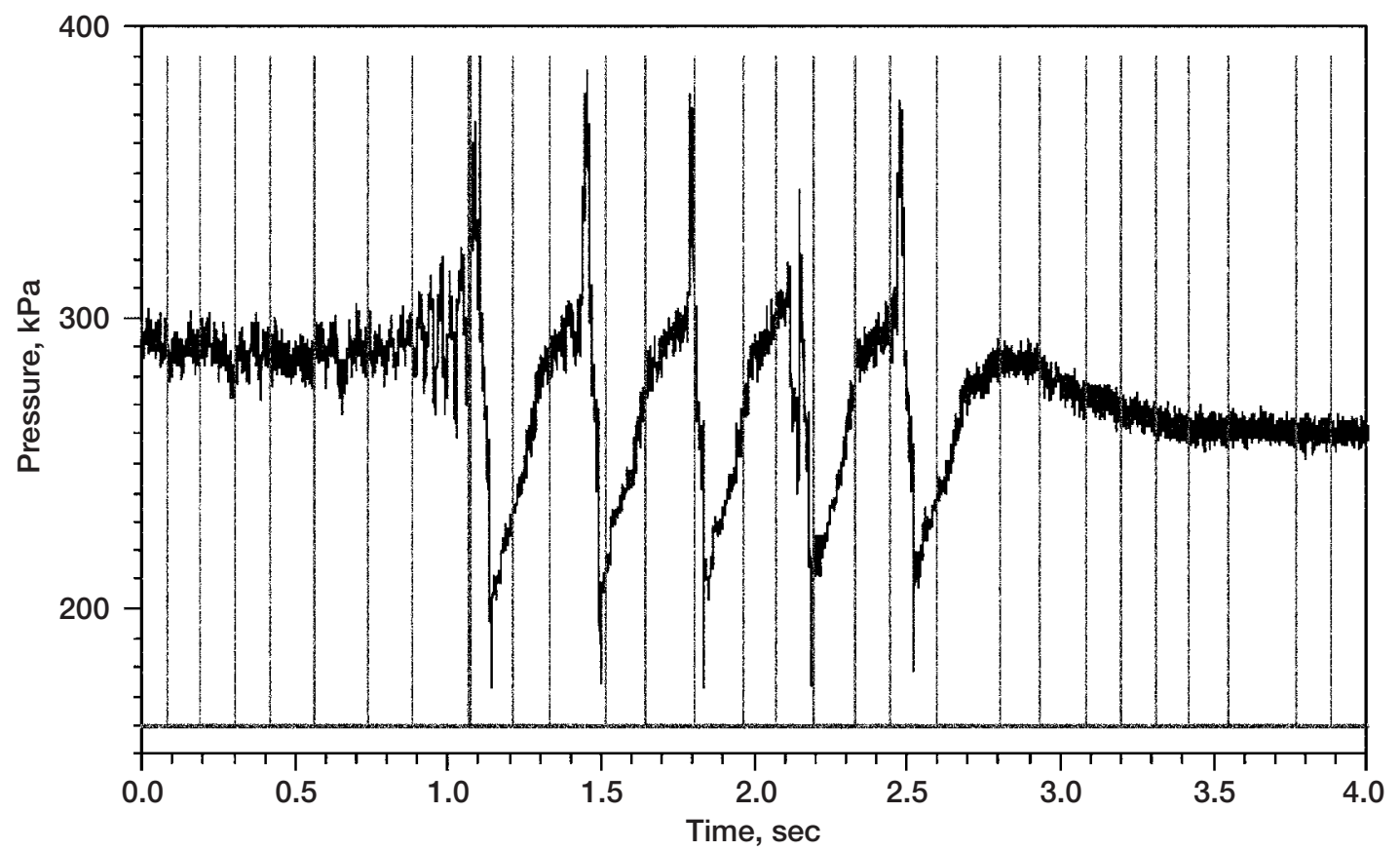

Figure 4.-Sample of the digitized Kulite \#3 signal along with the laser Q-switch trigger signals (narrow spikes) showing a complete surge event. 

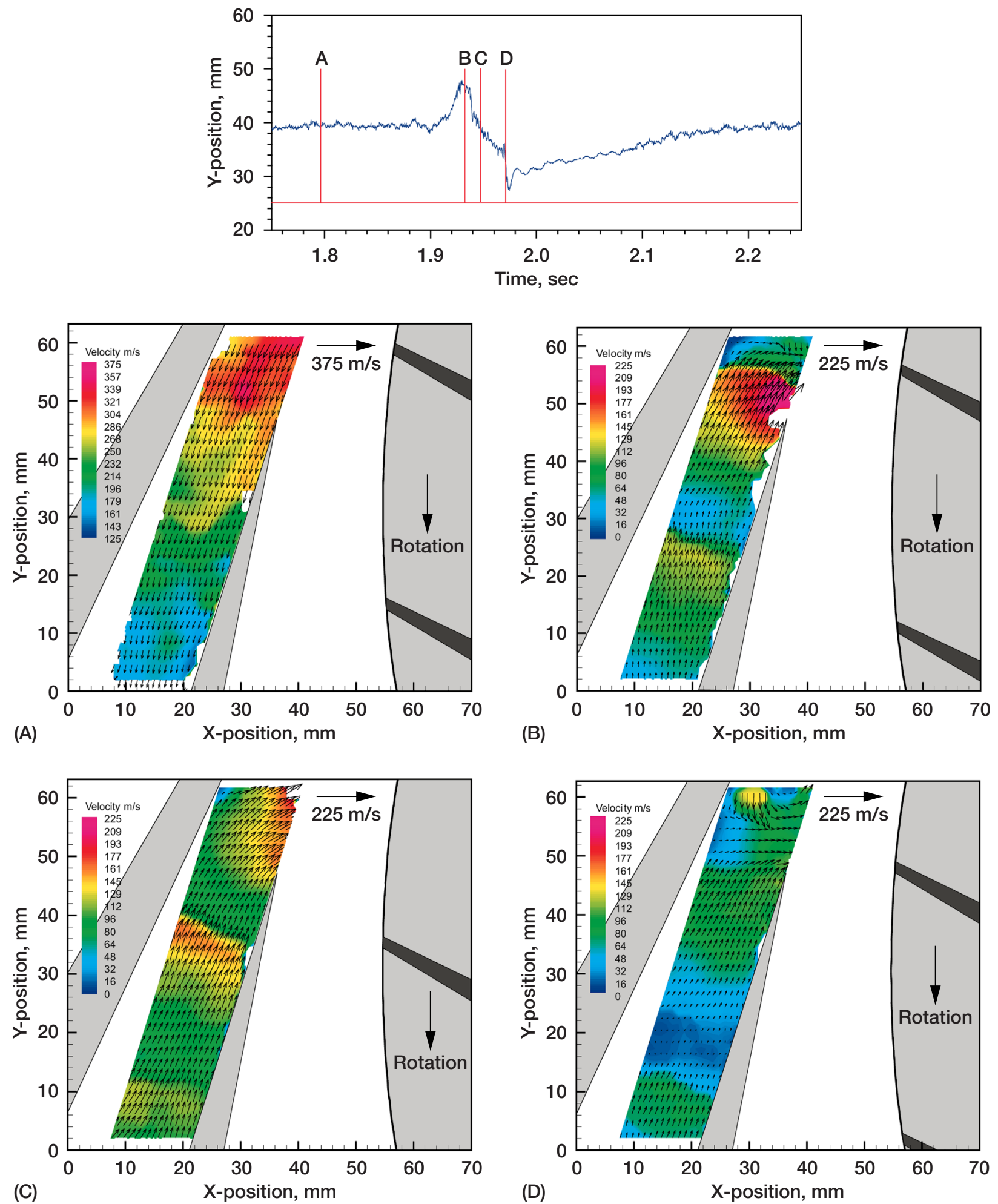

Figure 5.-Pressure time history measured using Kulite \#3 during a surge event is shown across top, where the labeled laser Q-switch trigger signals indicate time location in surge cycle of each respective velocity vector plot (velocity scale in plot $A$ is not the same as the scales in plots $B-D)$. (A) normal flow before the onset of surge; (B) reverse flow field at peak of high pressure surge cycle; (C) reverse flow field on the falling edge of the high pressure surge cycle; (D) reverse flow at the transition between the high pressure and low pressure portion of the surge cycle. 

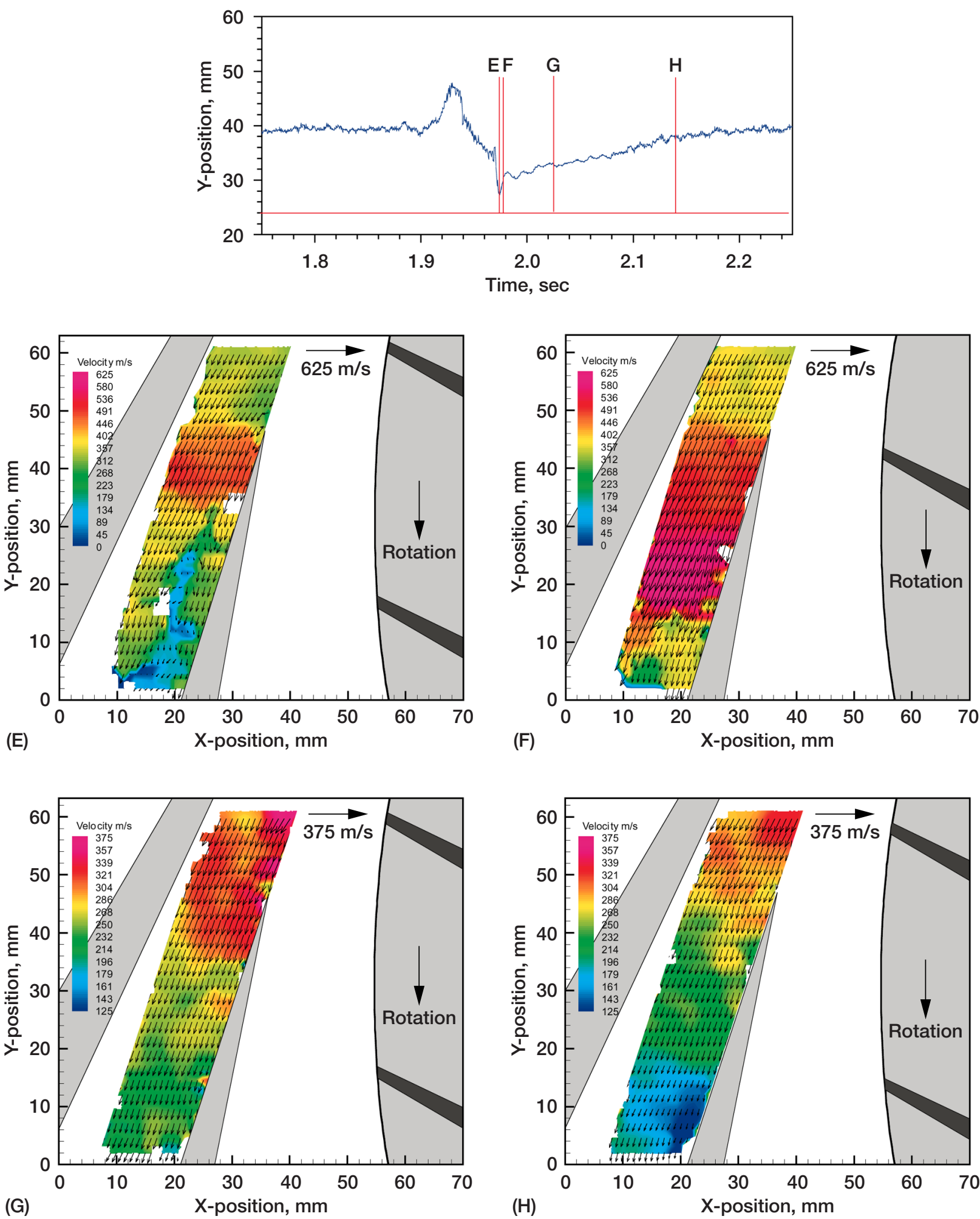

Figure 6.-Pressure time history during a surge event is shown across top, where the labeled laser Q-switch trigger signals indicate time location in surge cycle of each respective velocity vector plot (velocity scales in plots $E$ and $F$ are the same, scales in plots $G$ and $H$ are the same). (E) initiation of forward flow in the diffuser; (F) minimum pressure and peak velocity in diffuser; (G) pressure recovery and flow deceleration in the diffuser; $(\mathrm{H})$ end of surge cycle and return to presurge conditions observed in Fig. 5A. 


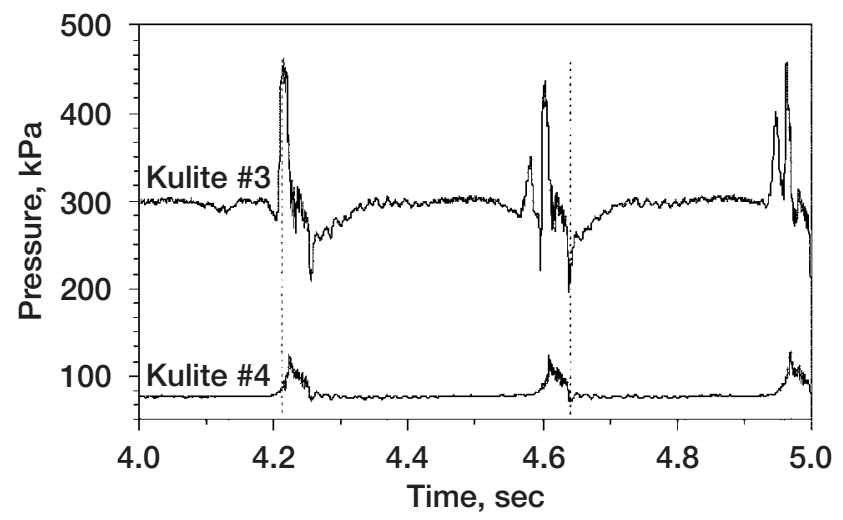

Figure 7.-Pressure traces for Kulites \#3 (diffuser throat) and \#4 (25 mm upstream of the impeller) during a surge event.
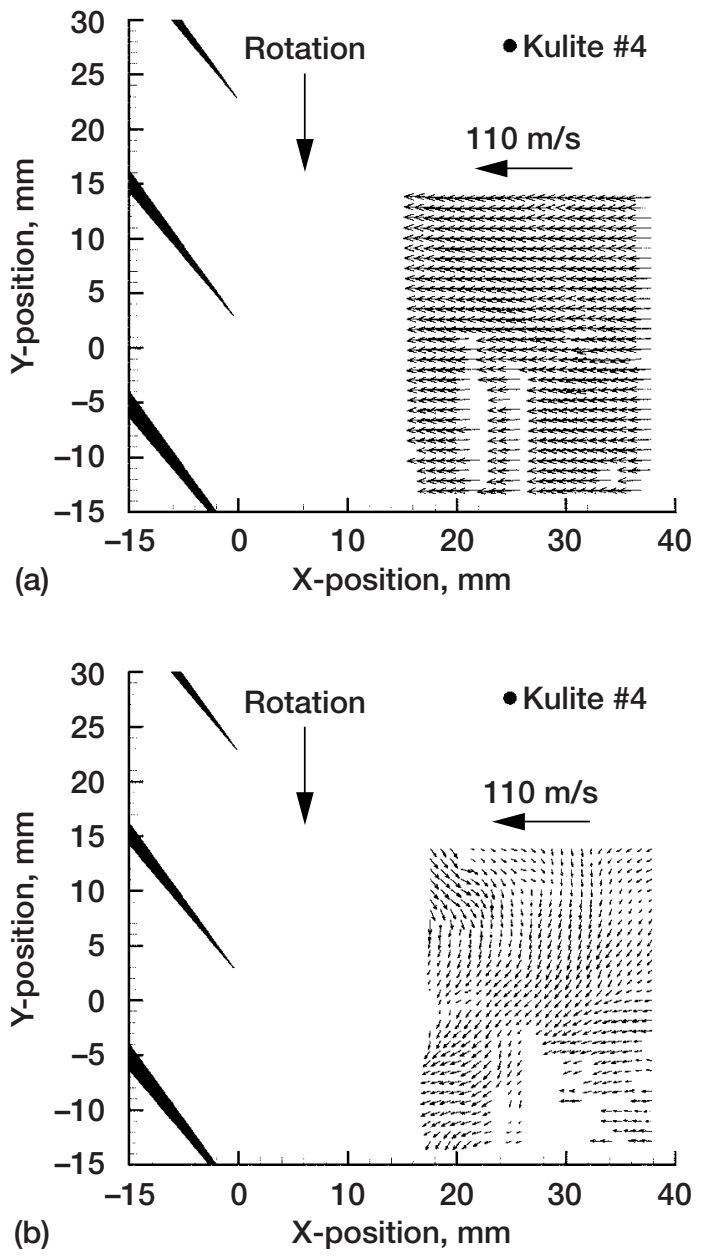

Figure 8.-PIV measurements (absolute reference frame) of the flow upstream of the impeller obtained at $10 \%$ span. (a) Steady flow field prior to surge; (b) reversing flow at the instant of peak static pressure observed at Kulite \#4. 

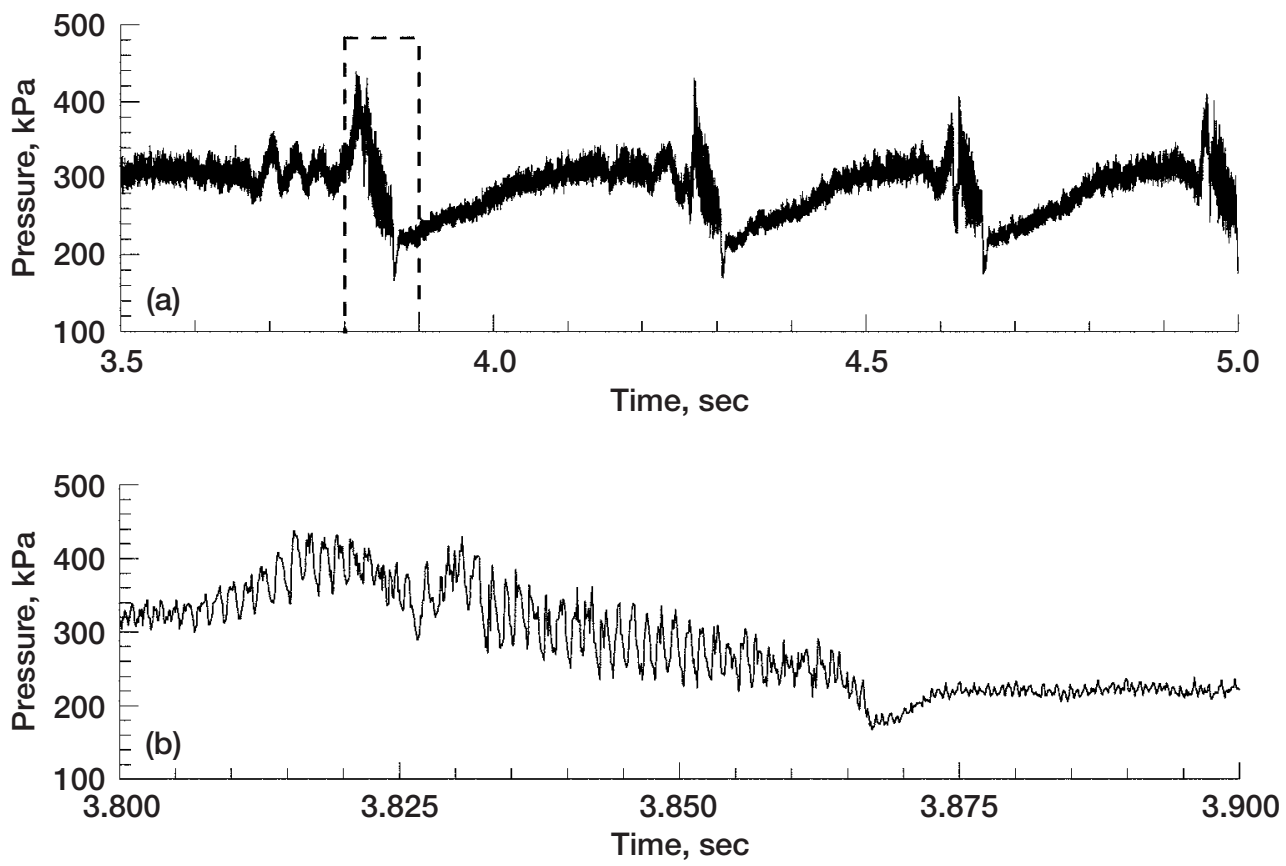

Figure 9.-Kulite \#3 signal digitized at $10 \mathrm{kHz}$, yielding an aliased dynamic pressure signal. (a) time record of several surge cycles; (b) expanded time record of the dashed box region from Fig. 9a. 


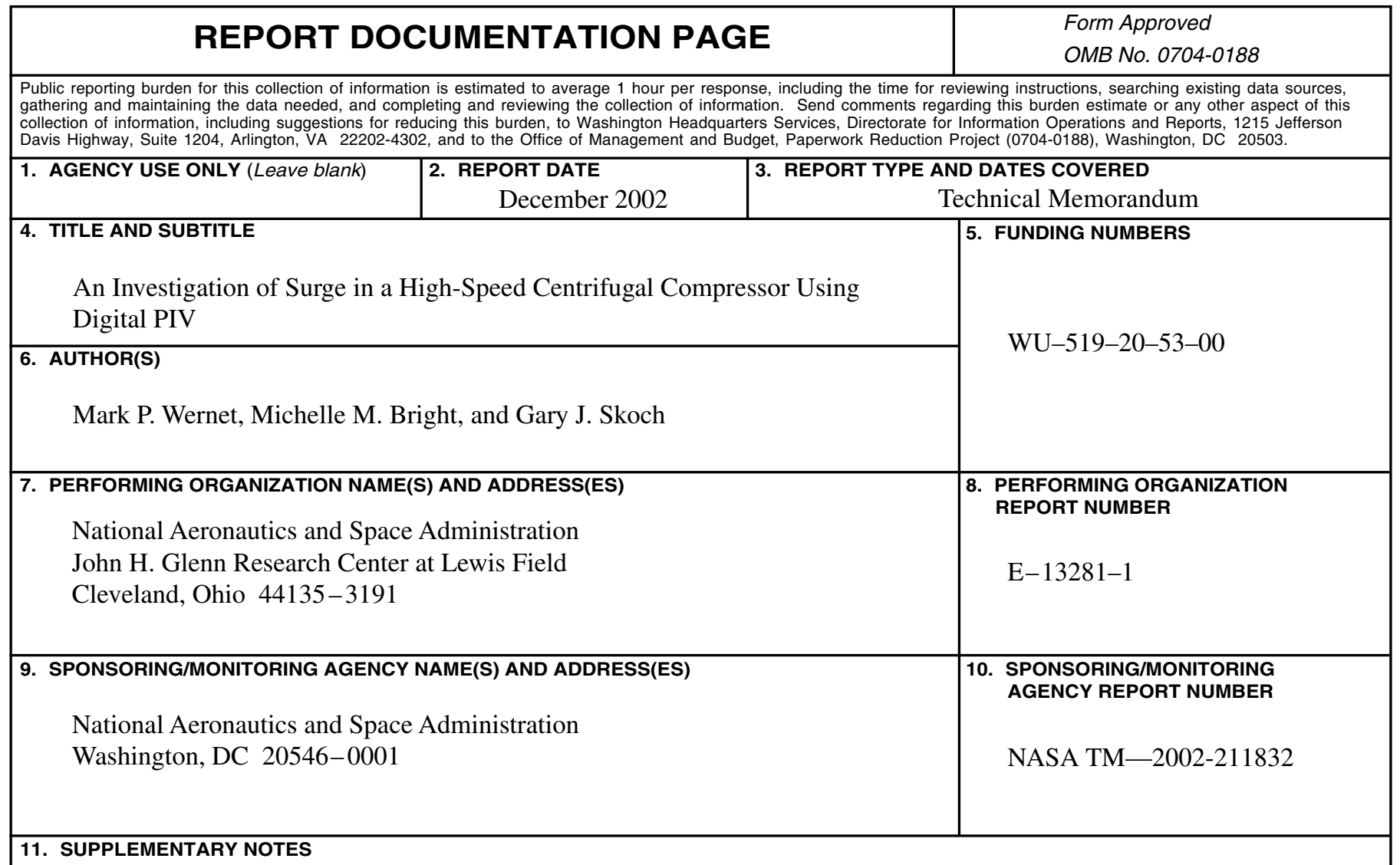

Mark P. Wernet and Michelle M. Bright, NASA Glenn Research Center; Gary J. Skoch, U.S. Army Research Laboratory, NASA Glenn Research Center. Responsible person, Mark P. Wernet, organization code 5520, 216-433-3752.

12a. DISTRIBUTION/AVAILABILITY STATEMENT

12b. DISTRIBUTION CODE

Unclassified - Unlimited

Subject Categories: 07 and 35

Distribution: Nonstandard

Available electronically at http://gltrs.grc.nasa.gov

This publication is available from the NASA Center for AeroSpace Information, 301-621-0390.

13. ABSTRACT (Maximum 200 words)

Compressor stall is a catastrophic breakdown of the flow in a compressor, which can lead to a loss of engine power, large pressure transients in the inlet/nacelle, and engine flameout. The implementation of active or passive strategies for controlling rotating stall and surge can significantly extend the stable operating range of a compressor without substantially sacrificing performance. It is crucial to identify the dynamic changes occurring in the flow field prior to rotating stall and surge in order to successfully control these events. Generally, pressure transducer measurements are made to capture the transient response of a compressor prior to rotating stall. In this investigation, Digital Particle Imaging Velocimetry (DPIV) is used in conjunction with dynamic pressure transducers to simultaneously capture transient velocity and pressure measurements in the non-stationary flow field during compressor surge. DPIV is an instantaneous, planar measurement technique which is ideally suited for studying transient flow phenomena in high speed turbomachinery and has been used previously to successfully map the stable operating point flow field in the diffuser of a high speed centrifugal compressor. Through the acquisition of both DPIV images and transient pressure data, the time evolution of the unsteady flow during surge is revealed.

\begin{tabular}{|l|l|l|}
\hline $\begin{array}{l}\text { 14. SUBJECT TERMS } \\
\text { Particle tracking; Velocimetry }\end{array}$ \\
\begin{tabular}{|c|c|} 
17. SECURITY CLASSIFICATION \\
OF REPORT \\
Unclassified
\end{tabular} & $\begin{array}{c}\text { 18. SECURITY CLASSIFICATION } \\
\text { OF THIS PAGE } \\
\text { Unclassified }\end{array}$ & $\begin{array}{c}\text { 19. SECURITY CLASSIFICATION } \\
\text { OF ABSTRACT } \\
\text { Unclassified }\end{array}$ \\
\hline
\end{tabular}

NSN 7540-01-280-5500

Standard Form 298 (Rev. 2-89)

Prescribed by ANSI Std. Z39-18 298-102 